\title{
Evolution of the Indian Health Insurance Sector: A review
}

\author{
Monica Bhatia ${ }^{1, *}$, Sachin Mittal $^{2}$, Alok Bansal ${ }^{3}$ \\ ${ }^{\mathbf{1}}$ Research Scholar, Devi Ahilya Vishwavidyalaya, Indore, Madhya Pradesh, ${ }^{\mathbf{2}}$ Assistant Professor, Jaipuria Institute of \\ Management, Indore, Madhya Pradesh, ${ }^{3}$ Professor, Prestige Institute of Management and Research, Indore, Madhya Pradesh, \\ India
}

*Corresponding Author

Email: bhatiam.017@gmail.com

\begin{abstract}
Health insurance is a mechanism that provides financial coverage for sickness or injury. Over the past few decades, India's achievement in terms of health improvement has been remarkable but health insurance industry is still way behind many other developing countries. This study examines the changes that have taken place in the Indian health insurance industry over a period of time and the issues and challenges the industry faces. The study utilized available data from more than 35 researches and relative studies conducted with respect to the health insurance sector. Not even a quarter of population in India is covered under any health insurance scheme. The penetration rate and expenditure on health insurance has been quite low. Penetration rate can be increased by means of micro-insurance, group insurance, government regulations over private sector and more schemes to reach out the rural masses with high competitive and service oriented delivery mechanism. However, the recent schemes and initiatives by government targeting the rural areas are becoming popular and may prove to be the appropriate way of supporting the society as a whole thereby saving it from the ruinous expenditure.
\end{abstract}

Keywords: Health insurance, Health care system, Penetration, Evolution of health insurance.

\section{Introduction}

The concept of insurance dates back to the ancient times where risk pooling was a phenomena people used to follow for their needs. But it was in the 90 s that formally health insurance came into being where the pooling of risk to substantiate the loss of fewer parties was structured. Health insurance helps a person to protect himself from financial loss that he may have to bear due to accident or disability. A study by Selvaraj and Karan (2009) based on National Sample Survey Organization (NSSO) data showed that nearly 39 million persons got into poverty by out-of-pocket medical expenses during 2004 as compared to 26 million in 1993-94. This number increased to 55 million in 2011-12 and the country's out-of-pocket expenditure for health was cited at 60 percent which is one of the highest in the world (Satapathy, 2016). With the help of health insurance policy, people can save themselves from the unseen financial burden they may have with respect to the health of any family member. Different policies have different coverage, different copayments and treatment options. However basic coverage includes medicines, doctor visits, emergency room visit and hospitalization expenses.

According to Vishwanathan (1996), "Health insurance is one of the measures of social security by which members of the community are assured benefits of both maintenance of health and medical care when they fall sick". In India, insurance is considered a federal subject which is governed by the Insurance Act, 1938 and the Insurance Regulatory and Development Authority Act, 1999. Since independence, status of healthcare has seen considerable growth; but still, India lags behind many other developing countries.
According to the Times of India, Economic survey, 2017, the country's public spending on health in just a 'little over' one percent of GDP and there are insufficient good models in the health sector. In 195051 , India's public spending on health was unusually low at 0.22 percent which has risen a little over one percent (as of Jan, 2017) but well below the world average of 5.99 percent. The survey said that as per Reserve Bank of India data, the expenditure on social services by Centre and States as a proportion of GDP was 7 percent during 2016-2017 with health sector accounting to 1.4 percent. According to an article under PolicyBazaar.com, the health insurance came to India in the form of Central Government Health Scheme (CGHS) for government employees and the Employee State Insurance Scheme (ESIS) for private sector employees but it was in 1986 that the first health insurance product was launched. Since then there have been many changes in the health insurance sector as with the government sponsored insurance companies, there are number of private sector players operating in India and offering differentiated products. After the independence of India, the health care system has seen expansion and modernization, with the availability of modern health care facilities and training medical personnel effectively (Ellis, et al, 2000).

Increasing income, health consciousness and private players are major reasons of growth of health insurance. Spaan et al. (2012) mentioned that health insurance is growing in middle and low income countries as it protects households from out-of-pocket expenses and improves healthcare utilization. 


\section{Objectives}

1. To understand the changes those have taken place in health insurance sector with time.

2. To identify the opportunities and challenges for the growth of Indian health insurance sector.

\section{Materials and Methods}

The Study: The study is exploratory in nature which explores the changes that have taken place in health insurance sector with time. The articles published from 1990s to 2017 were analysed that were retrieved using the search strategy that best matches the study objective.

The Sample: The relevant data comprised of articles, journals, books and literature available on internet from various research organizations and government establishments. Total 38 articles were reviewed for study.

Data Analysis: As the study is exploratory, and based on the review of literature, no statistical tools have been applied. Health insurance industry surrounds itself with number of systems that are interactive and not work in isolation. Therefore, the study could not be limited to a particular development but revolved around several interactive issues that have made a prominent mark in the development of the entire healthcare industry in India.

\section{The Review of Literature}

Anand and Ravallion (1993) in the study of "human development in poor countries", found that, for basic health, affluence is considered to the extent that it delivers lower income poverty and better public services. The study found that usually observed positive correlation across countries between life expectancy and affluence diminishes when one control for incidence of poverty and public spending on health. Though both these variables matter, there was more significance of public health spending that was prominent. Ramamani (1995) in "household survey of healthcare utilization and expenditure" found that, the cases of reported hospitalization were considerably higher in urban areas, reflecting the differences of the regions to hospital access. Correspondingly, the percentage of untreated illnesses was found higher in rural areas. The study also revealed that for out-patient care, there was a high dependence on private sector facilities and this dependence was found to be higher for higher income groups.

Raman and Warner (1996) in the study of private public partnership in healthcare services in India, concluded that poor patients have been profited by public-private partnership and though such partnerships cannot be similar across all areas for their political and administrative differences, the initial step should be to improve basic administrative systems which helps the government to deliver quality social services and provide clinical and nonclinical services effectively.
Ranode and Abuja (1999) identified strategic issues in liberalization. The study brought out the need of private players in insurance and suggested that it enhances operational efficiency and achieves greater density and penetration thereby bringing freedom of investment and adoption to the liberalized scenario.

Dhingra (2001) found that the NGO sector was all set to play a vital role in financing health care through health insurance schemes. The finding suggested that this will have an impact on the system of health care delivery and payment mechanisms in the country. Though in such a situation, primarily, the interests of the poor and under privileged sections of the society need to be guarded by appropriate regulatory mechanisms so as to ensure equity and efficiency in the provision of health care. Devadasan et al. (2004) highlighted that India is considered to have a very high out-of-pocket healthcare expenditure and it is important to take certain measures to protect the poor people. Community health insurance was a feasible alternative; given that community based organisations exist in India. But regulating the providers and to legislate is imperative for the community health insurance programmes to have a space within the Indian insurance context. Ahuja (2005) studied "insurance for the poor". The study brought out the role of nodal agency in extending health insurance and discussed how health insurance for the poor was different from health insurance in general. The study also highlighted that depending on the functions that a nodal agency performed, micro insurance arrangements in the country could be categorized into three distinct types: intermediate type, manager type and provider type. All these types may be appropriate for a large and diverse country like India. The study analysed selected conceptual issues that were generic to all types of health insurance initiatives as well as those that were specific to a particular type and also suggested that a good understanding of these issues is important to remove some of the weakness in the design of health insurance.

Gangolli et al. (2005) analysed that majority of the population in India lives below poverty line. This states that 70 to 90 percent of their income is spent on food and related consumption. In this kind of scenario, social support for health and other basic amenities becomes critical. The study further indicated that avoidance of public health sector is a big issue than altogether making a government policy. Ramani and Mavalankar (2005) based on the analysis of opportunities and challenges for improvement in health system in India, pointed out the roles of various stakeholders in improving health sector; like government should promote social healthcare insurance and scale up the financial resource, protect the poor against ill health and exploitation and ensure quality improvements through standards and accreditations. The analysis also stated that corporate sector should provide high quality 
evidence based medical services at reasonable costs by developing cross-subsidising mechanism.

Bhat and Jain (2006) in the study of "factors affecting demand for health insurance in a micro insurance scheme", found income to be an important factor. The study came up with a finding that higher income increases the probability of purchasing health insurance. IRDA needs to take definitive steps to promote and develop private insurance sector and give special attention to micro insurance and community based health insurance schemes. It may also consider creating a technical support organization for micro insurance schemes. Number of children in the family was also found to be an important factor. The study also suggested that households with more number of children spend more on health insurance. Asoh and Rivers (2007) explained that one of the major challenges is the high system cost. It was found that the effect of competition on cost and quality was previously analysed independently and therefore causes confusion. The study recommended that these issues be examined simultaneously as they are inter-related.

Vellakkal (2007) had the view that health insurance is a solution that provides access to basic healthcare services. The number of people with health insurance coverage was very low in India probably because of some structural issues with the system. To assure equity in health insurance coverage, there was a strong need of government intervention in health insurance market. The study also examined that the insurance agents play a key role in scaling up the process of Private Health Insurance (PHI) in India. Card et al. (2007) stated that insurance coverage has a significant causal effect on treatment intensity, case disposition, and health outcomes. It was revealed that patients with no coverage or relatively limited coverage receive less intensive treatment and are more likely to be discharged from the hospital in an unhealthy condition rather than transferred to another hospital or unit within the same hospital for continued care.

Amponsah and Hiemenz (2009) investigated the empirical relationship between healthcare providers and satisfaction with health care. The study found that users of private and public healthcare facilities are likely to be more satisfied with health services than their counterparts who seek health care from traditional healers, pharmacies or over-the-counter drugs and therefore pay for them out of their pockets. It was also revealed that customers of private health services were approximately 12 percent more likely to be satisfied than subscribers of public health care. Ghuman and Mehta (2009) under the study of "health care services in India: Problems and Prospects", analysed that public expenditure incurred on health in India needs to be increased along with reducing the regional disparities in the provision of health services. Poor and backward states lagging behind need quantum jump in the level of funding of health services. The study revealed that the implementation of National Rural Health Mission (NRHM) should be speeded up that provides more access to health services to the rural people in general and poor in particular.

Kumar and Gupta (2012) studied Health infrastructure and suggested that government should increase the expenditure on health from one to around three percent of GDP. The government must focus on the healthcare infrastructure both qualitatively as well as quantitatively. Pahuja and Vohra (2012) concluded that along with the initiatives taken by government regarding infrastructure requirements, the need for technology solutions has tremendously increased. In the absence of technology solutions, the healthcare sector cannot achieve its full potential as there would be cases of excess and insufficient capacity of specialized services at various locations. A priority based hub and spoke model implementation can help in minimizing the gaps and direct the patients to nearest and right medical facility which can be achieved with the help of integration. According to Prinja et al. (2012), in the study "Universal Health Insurance in India: Ensuring Equity, Efficiency and Quality", additional efforts are required for MIS that is critical for successful monitoring of claims, setting of premiums etc. Forgia and Nagpal (2012) mentioned that there have been many factors associated with the development of Government Sponsored Health Insurance Schemes (GSHISs) like the efficiency of health financing arrangements, reach and performance of service delivery and the evolution of risk - protection mechanisms. This gets especially true for the schemes which as a group, were launched in response to the challenges and opportunities evidently seen in the health system.

Sheth (2014) indicated that the underfunding of medical services is a matter of serious concern. The need for more resources and greater decentralization has to be taken up on a priority basis. There is an urgent need for regulation and monitoring of the private health sector. Large sections of the population have become pauperized due to the large sums of money spent on private healthcare. To achieve universal access to healthcare and relative equity, the State has to play the lead role. This is perhaps the only alternative available at present in order to ensure the healthcare facilities to the population. Daikh (2015) suggested that future researches must utilise new technologies to measure service quality. Relationship between service quality, customer satisfaction and loyalty helps in targeting the customers efficiently. According to Desai (2016), there are many advantages of foreign investment in hospitals and other healthcare services especially medical device, diagnostics, and e-Health like necessary infrastructure, rise in standards of healthcare, technology upgradation and increase in employment. However, the cost of medical care should be affordable especially in the Tier 2 
and Tier 3 locations as there is a high growth potential and lack of quality healthcare services.

Chaudhry (2017) in "Mega trends in Indian Insurance Industry" came up with a view that insurance business will not be saved by the "mega-trend" of 'digitization' that is going to be irreversible in the coming years. This 'going digital' will manifest itself in more ways than one for customers, distributors as well as back-office operations of insurers. Mobile devices that are always 'on' allow for more personalized interactions where insurers can reach the customers like never before. Based on internal and external data sets, insurers can get deep insight into customer behaviour. Also, features like biometric identification can help prevent fraud securing customer's personal data. In this hyper connective world, insurers can also build digital ecosystems for different product categories. Dasgupta (2017) concluded that the issues behind low penetration of non-life insurance should be identified collectively and solutions must be reached. Industry players should take a look at the success of recent government schemes for answers. The Pradhan Mantri Fasal Bima Yojana (PMFBY) drove up the crop insurance coverage from 23 to 29 percent within a year of its launch. In the similar way, the Rail Insurance scheme has already covered 9 crore passengers since its inception in 2016. The multiple reasons for the success of such schemes should be studied like involvement of stakeholders, forward-looking policy framework as well as the use of technology to reach out masses and thus can be applied in the health insurance sector to expand its penetration. Prinja et al. (2017) observed that with the current policy directions for universal health care, publicly financed health insurance schemes are here to stay. There is a need for designing the schemes and implement safeguards to maximize the benefits of risk pooling. These benefits can be fully reaped when the health care infrastructure for delivery of health services is strong. Also, the public sector should be strengthened to compete for provision of services. This will in turn generate extra revenue for public health system.

\section{Discussion}

The study is a chronological and systematic review to examine the health insurance sector and the changes that have come through from time to time. The review is based on the above studies and other related literature and points that despite that the health insurance sector has been extensively studied; most of the researches cover one or two areas affecting the health insurance in the country. It is evident that the overall growth of the health insurance sector depends on many aspects like government initiatives, regulatory framework, role of hospitals, policy framework, insurance companies and their services etc.

1990 - 2000: The studies conducted in the period between 1990 and 2000 focused on public health spending and public private partnerships that were beneficial to the poor patients. A high percentage of untreated illness was found in rural areas and the dependence of out-patient care was on private sector facilities. The decade saw the need for private players in the health insurance industry suggesting that it leads to greater penetration and higher density.

2000 - 2005: The studies conducted between 2000 and 2005 were more inclined towards the regulatory mechanism and strategies for deep penetration of the health insurance. The review suggested that role of nodal agency, NGOs and Community health insurance was feasible and imperative for the overall growth of the sector. The role of various stakeholders like government, regulators and insurance companies was also given importance to raise the financial resources and protect the poor.

2006 - 2010: Demographic factors started taking over in the late 2000s. Income became an important factor as individuals with higher income were found purchasing the health insurance policies more than the ones with comparatively lower income. The households with more number of children spent more on health insurance. The major challenge of this time was the high system cost and need of government intervention still prevailed. The studies suggested that patients with no or less coverage were more likely to be discharged in an unhealthy condition and were less satisfied than the ones with the health insurance coverage. Also, private health insurance customers were more satisfied than public health insurance customers and therefore, public health system needed to be more qualitative to be at par with the private sector.

2011 onwards: Studies conducted after 2010 highlighted the factors like infrastructure and technology. Government intervention and the need of higher regulatory mechanism still prevail. This era shifts itself to service quality and customer satisfaction as with digitization, people have access to all the information they need and are more aware than ever before. Foreign investment holds its positive outcomes and the studies suggested that it helps in raising the standards and quality of the necessary infrastructure and technology upgradation also creating employment opportunities at large.

According to the study, factors like cost of policy, income and competition gained more importance somewhere around 2010 where the health insurance sector became more competitive with private sector coming up with differentiated products to tap the market. However, customer satisfaction and infrastructure became prominent issues and therefore, health insurance sector even went digital and now it was possible to pay the premiums and track the policy online. Consumers with the World Wide Web were able to compare the different policies available to them and make a proper and corrective decision.

The study also found that one of the major issues in the health insurance industry has been the insurance for 
the poor and that the necessary steps should be taken to reach out the masses that may have to deal with economic hardships if they do not fall under a formal and organised insurance scheme. Insurance for the poor and government intervention in the sector has been important in the 90s and still is. However, the scheme of Ayushman Bharat launched by the Government is a major change in the Indian Health Insurance sector. High system cost has been another major concern as it restricts lower middle and lower income group to enter the health insurance and save them from the unseen expenditure. Less public spending by Centre and State also creates a big hurdle in the growth of the sector. The review suggested the Government to increase the share of healthcare expenditure from one percent of GDP to around three percent.

Indian health insurance industry faces a major challenge of making people aware especially in the rural areas about the needs and benefits of health insurance. Though, with the help of technology and government initiatives, this class is also getting tapped but still there is a lot to be done. The review overall suggested government focus to be of prime importance in terms of its own schemes and regulating the private market to allowing the foreign investment in the sector.

This sector has grown manifolds and will continue to grow, given the importance of health insurance as a system and awareness of public. However, there is much more to this sector. According to a Times of India article, in 2016, 80 percent of Indian population was not covered under any health insurance plan - private or public. The government though brought about $12 \%$ urban and $13 \%$ rural population under Rashtriya Swashtya Bima Yojana (RSBY), Employee State Insurance Scheme (ESIS) and Central Government Health Scheme (CGHS) for unorganised workers, organised workers and government employees respectively. The survey also reflected that more and more people were accessing private facilities thereby putting themselves under a big financial burden. The available evidences clearly demonstrate that health insurance is a better alternative to user fees as a health financing mechanism.

\section{Conclusion}

One of the important conclusions derived from the literature study is that the health insurance industry has overall become multi-faceted and there cannot be one aspect of its development but many factors that are interlinked and interrelated.

It continues to expand and be technologically driven in order to reach masses and to ensure high quality and cost effective services. Today, the biggest challenge for health insurance industry in India is insuring the people below poverty line. The high cost of premium and facilities is beyond the reach of these individuals. Private practitioners, doctors and pharmacies work with the sole motive of increasing profitability rather than supporting the society. Therefore, government intervention is required to control the costs of system and also regulate these private players that may cause the financially challenged individuals to end up paying more than the worth of service. There is no doubt that the regulations are increased by Insurance Regulatory and Development Authority of India (IRDAI) and the intent of government coming with health insurance schemes prove sustainable ensuring affordable healthcare to the population. Present era has seen many changes in health insurance sector with the Government of India launching schemes especially for the rural areas. Although the pre-existing Rashtriya Swashtya Bima Yojana (RSBY) has its own benefits, the new schemes like Ayushman Bharat gave a new ray of hope to save the hard earned money of an individual from the unseen medical emergency one may have to face.

The importance of health insurance becomes more prominent due to rise in the medical costs and increasing financial burden. Ahuja (2004) mentioned that it is to be understood that health insurance per se is just a financing mechanism which does not guarantee efficient delivery of health services. Expanding the health insurance without considering the availability of medical services may not serve any purpose (Bhat and Saha, 2004). Thus, more and more hospitals should be networked and the facilities provided by them should be regulated so as to ensure effectiveness of healthcare system as a whole. Eighty percent of Indian population is not yet covered, which clearly shows that India is a very big market for health insurance industry and a big opportunity for government and private players. Penetration rate can be increased by means of microinsurance, group insurance, government regulations over private sector and more schemes to reach out the rural masses with high competitive and service oriented delivery mechanism. It takes the combined effort of all the stake holders like companies, regulators and third party agents to enhance the penetration of health insurance sector in India.

The health insurance sector is growing at a speedy rate and the key developments took place post privatisation. Dasgupta (2017) indicated that health insurance is one of the few industries that carry a noble cause with social benefit also providing support to nation and the government. As a society, we must collectively support its growth and development. The industry has a great growth potential and given the right stimuli it can double in size by 2020 . Government can offer service tax benefits that will encourage companies to reach out masses thereby providing more services. On the other hand, private players rather than charging high premium and having a small proportion of population can work towards increasing their base by reducing the cost of premium. This will be beneficial to both the private sector and the society at large. Also, the study suggests and preaches that "precaution is better 
than cure'. If the government works on infrastructure and society supports and maintains cleanliness in the surroundings, there would be less people falling sick and less claiming of health insurance policies thereby reducing the cost the companies incur. Thus, if the above suggestions are followed, it becomes a two way beneficial process.

\section{References}

1. Ahuja, R. Insurance: Over the Transition. Economic and Political Weekly: 2004;39(32):3569-71.

2. Ahuja, R. Health Insurance for the Poor in India: An analytical Study. Indian Council for Research on International Economic Relations. 2005.

3. Amponsah E.N., Hiemenz U. Determinants of Consumer Satisfaction of Health Care in Ghana: Does Choice of Health Care Provider Matter?. Global Journal of Health Science, 2009;1 (2).

4. Anand S., Ravallion M. Human Development in Poor Countries: On the Role of Private Incomes and Public Services. Journal of Economic Perspectives: 1993;7(1):133-50.

5. Asoh D.A., Rivers P.A. A Research Model of HealthCare Competition and Customer Satisfaction. Health Services Management Research:2007.

6. Bhat R., Jain N. Factors affecting the Demand for Health Insurance in a Micro Insurance Scheme. Indian Institute of Management, Ahmedabad, Research and Publications, W.P. No. 2006-07-02.

7. Bhat R., Saha S. Health Insurance: Not a Panacea. Economic and Political Weekly: 2004;39(33):3667-70.

8. Card D., Dobkin C., Maestas N. Insurance Status on Treatment Intensity and Health Outcomes, RAND, 2009; WR-505.

9. Chaudhry, A. Mega Trends in Indian Insurance Industry. The Boston Consulting Group - FICCI: The Changing Face of Indian Insurance:2017;14-6.

10. Daikh, J. The Relationship Between Customer Satisfaction and Consumer Loyalty. Johnson \& Wales University: 2015.

11. Dasgupta, B. Insurance - Gearing up for New Age Trends. The Boston Consulting Group - FICCI: The Changing Face of Indian Insurance: 2017;17-9.

12. Desai, N. Investment in Healthcare Sector in India. Nishith Desai Associates Research Paper: 2016.

13. Devadasan N, Kent R., Wim V.D., Bart C. Community Health Insurance in India - An Overview. Economic and Political Weekly, July 10, 2004.

14. Dhingra, R. NGOs and Health Insurance Schemes in India. Health and Population - Perspectives and Issues: 2001;24 (4):206-17.

15. Ellis P.R., Alam M., Gupta I. Health Insurance in India: Prognosis and Prospectus. Economic and Political Weekly: 2000;35(4):207-17.

16. Forgia G.L., Nagpal S. Government Sponsored Health Insurance in India: Are You Covered?. The World Bank Directions in Development - Human Development, 72238. 2012 (Google Books).

17. Gangolli L.V., Duggal R., Shukla A. Review of Healthcare in India. Centre for Enquiry into Health and Allied Themes. 2005.

18. Ghuman B.S., Mehta A. Health Care Services in IndiaProblems and Prospects. International Conference - The Asian Social Protection in Comparative Perspective, National University of Singapore. 2009.

19. Kumar, A., Gupta, S. Health Infrastructure in India: Critical Analysis of Policy Gaps in the Indian Healthcare
Delivery. Vivekananda International Foundation, Occasional Paper. 2012.

20. Pahuja G., Vohra R. Indian Healthcare Sector - A Technology Approach for Efficiency Improvement: 2012; www.ijarscce.com.

21. Prinja S., Chauhan A. S., Karan A., Kaur Gunjeet, Kumar R. Impact of Publicly Financed Health Insurance Schemes on Healthcare Utilization and Financial Risk Protection in India: A Systematic Review. PLOS One 2017;12(2):e 0170996, PMC5289511.

22. Prinja S., Kaur Manmeet, Kumar R. Universal Health Insurance in India: Are You Covered?. Indian Journal of Community Medicine: 2012 Jul-Sep; 37(3):142-9, PMC3483505.

23. Ramamani, S. Household Survey of Healthcare Utilization and Expenditure. NCAER, 1995;W.P. No. 53.

24. Raman A.V., Warner B.J. Public/Private Partnership in Health Care Services in India. 1996; project 5.3.96.

25. Ramani K.V., Mavalankar D. Health system in India: Opportunities and Challenges for Improvement. Indian Institute of Management, Ahmedabad, Research and Publications, W.P. No. 2005-07-03.

26. Ranode A., Abuja R. Life Insurance in India - Emerging Issues. Economic and Political Weekly. Jan 1999:16-23.

27. Satapathy, S. Minimizing out-of-pocket Health Expenditure for India's Poor. 2016; https://www.devex.com/news.

28. Selvaraj, S.A. Deepening Health Security in India: Evidence from National Sample Surveys since 1980s. Economic and Political Weekly: 2009; 44 (40):55-60.

29. Sheth, H. Changing Trends in the Healthcare Sector in India. Abhinav International Refereed Journal of Research in Management and Technology: 2015;3(9), ISSN - 2320-0073.

30. Spaan E., Mathijssen J., Tromp N., McBain F., Have A., Baltussen R. The Impact of Health Insurance in Africa and Asia: a systematic review. Bull World Health Organization: 2012; 90:685 - 92(A).

31. Vellakkal, S. Health Insurance Schemes in India: An Economic Analysis of Demand Management under Risk Pooling and Adverse Selection. A Thesis - University of Mangalore:2007.

32. Vishwanathan, R. Health Insurance and Medical Services. Indian Journal of Social Work: 1996;12(1):70 3. http://www.rsby.gov.in/overview.aspx http://www.irda.gov.in/Defaulthome.aspx?page=H1 https://www.policybazaar.com/health-insurance/generalinfo/articles/a-glance-at-the-evolution-of-healthinsurance-in-india/ https://www.businessinsider.in/8-Insurance-SchemesModi-launched-and-how-they-benefityou/articleshow/47418104.cms https://timesofindia.indiatimes.com/business/economicsurvey/economic-survey-says-indias-public-spending-onhealth-well-below-globalaverage/articleshow/56897993.cms 